\title{
BMJ Global Health Using a mentorship model to localise the Practical Approach to Care Kit (PACK): from South Africa to Ethiopia
}

\author{
Yibeltal Mekonnen Feyissa, ${ }^{1}$ Charlotte Hanlon, ${ }^{2,3,4}$ Solomon Emyu, ${ }^{5}$ \\ Ruth Vania Cornick, ${ }^{6,7}$ Lara Fairall, ${ }^{6,7}$ Daniel Gebremichael, ${ }^{1}$ Telahun Teka, \\ Solomon Shiferaw, ${ }^{8}$ Wubaye Walelgne, ${ }^{1}$ Yoseph Mamo, ${ }^{9,10}$ Hailemariam Segni, ${ }^{11}$ \\ Temesgen Ayehu, ${ }^{1}$ Meseret Wale, ${ }^{1}$ Tracy Eastman, ${ }^{6,12}$ Ajibola Awotiwon, ${ }^{6}$ \\ Camilla Wattrus, ${ }^{6}$ Sandy Claire Picken, ${ }^{6}$ Christy-Joy Ras, ${ }^{6}$ Lauren Anderson, ${ }^{6}$ \\ Tanya Doherty, ${ }^{13}$ Martin James Prince, ${ }^{2,14}$ Desalegn Tegabu ${ }^{1}$
}

To cite: Feyissa YM, Hanlon C, Emyu S, et al. Using a mentorship model to localise the Practical Approach to Care Kit (PACK): from South Africa to Ethiopia. BMJ Glob Health 2019;3:e001108. doi:10.1136/ bmjgh-2018-001108

Handling editor Seye Abimbola

- Additional material is published online only. To view please visit the journal online (http://dx.doi.org/10.1136/ bmjgh-2018-001108).

YMF and $\mathrm{CH}$ are joint first authors.

Received 13 August 2018 Revised 16 0ctober 2018 Accepted 17 October 2018

Check for updates

(C) Author(s) (or their employer(s)) 2018. Re-use permitted under CC BY-NC. No commercial re-use. See rights and permissions. Published by BMJ.

For numbered affiliations see end of article.

Correspondence to Dr Charlotte Hanlon; charlotte.hanlon@kcl.ac.uk

\section{ABSTRACT}

The Federal Ministry of Health, Ethiopia, recognised the potential of the Practical Approach to Care Kit (PACK) programme to promote integrated, comprehensive and evidence-informed primary care as a means to achieving universal health coverage. Localisation of the PACK guide to become the 'Ethiopian Primary Health Care Clinical Guidelines' (PHCG) was spearheaded by a core team of Ethiopian policy and technical experts, mentored by the Knowledge Translation Unit, University of Cape Town. A research collaboration, ASSET (heAlth Systems StrEng Thening in sub-Saharan Africa), has brought together policy-makers from the Ministry of Health and health systems researchers from Ethiopia (Addis Ababa University) and overseas partners for the PACK localisation process, and will develop, implement and evaluate health systems strengthening interventions needed for a successful scale-up of the Ethiopian PHCG. Localisation of PACK for Ethiopia included expanding the guide to include a wider range of infectious diseases and an expanded age range (from 5 to 15 years). Early feedback from front-line primary healthcare $(\mathrm{PHC})$ workers is positive: the guide gives them greater confidence and is easy to understand and use. A training cascade has been initiated, with a view to implementing in $400 \mathrm{PHC}$ facilities in phase 1 , followed by scale-up to all 3724 health centres in Ethiopia during 2019. Monitoring and evaluation of the Ministry of Health implementation at scale will be complemented by indepth evaluation by ASSET in demonstration districts. Anticipated challenges include availability of essential medications and laboratory investigations and the need for additional training and supervisory support to deliver care for non-communicable diseases and mental health. The strong leadership from the Ministry of Health of Ethiopia combined with a productive collaboration with health systems research partners can help to ensure that Ethiopian PHCG achieves standardisation of clinical practice at the primary care level and quality healthcare for all.

\section{Summary box}

The Ethiopian Federal Ministry of Health has localised the Practical Approach to Care Kit (PACK) programme to become the Ethiopian Primary Health Care Clinical Guidelines (PHCG).

- The purpose of the Ethiopia PHCG programme is to address concerns about the quality and standardisation of care received in primary care settings.

- Localisation of PACK included expansion of content to include the 5-15 years age group, common infectious disease presentations and customisation of symptom presentations.

- From the outset, there has been close working between the Federal Ministry of Health and a research collaboration (ASSET, heAlth Systems StrEng Thening in sub-Saharan Africa) focused on health systems strengthening to support the scale-up of Ethiopian PHCG.

- Implementation and scale-up of the Ethiopian PHCG will be a key tool in primary healthcare transformation to achieve universal health coverage.

\section{INTRODUCTION}

Forty years on from the Alma Ata Declaration, primary healthcare (PHC) is getting renewed attention as the key means through which universal health coverage can be achieved. ${ }^{1}$ However, the quality of primary care services in many countries of sub-Saharan Africa has been found to be generally poor and highly variable. ${ }^{2}$ This has led to calls to prioritise interventions to improve the quality of PHC to achieve effective coverage of care. ${ }^{3}$

Ethiopia is located in the Horn of Africa and is the second most populous country in sub-Saharan Africa, with an estimated population of 105 million, $42 \%$ of whom are under the age of 15 years. ${ }^{4}$ The country is predominantly rural, with only $20.2 \%$ of the population living 
in towns. ${ }^{5}$ In recent years, Ethiopia has been noted for its flagship Health Extension Programme, comprising 39 878 salaried community-based health extension workers in 2017, which has facilitated expansion of access to PHC. ${ }^{6}$ The focus of the Health Extension Programme is on health promotion and disease prevention, with health extension workers playing a key role in bridging the cultural and information divide that underlies low community demand for healthcare (an average of only 0.8 outpatient contacts per person per year). ${ }^{6}$ However, in spite of notable successes, for example, in the area of maternal and child health, ${ }^{7}$ concerns remain about the quality and scope of facility-based PHC. ${ }^{8}$ This has prompted a broadening of focus from access to care alone to encompass equity of access and the quality of care available at the PHC level, articulated in the current Health Sector Transformation Plan. ${ }^{8}$ Ethiopia has a universal health coverage target of $85 \%$ of essential services to be provided by the public sector by $2020 .{ }^{8}$ To achieve this, various initiatives are under way: implementation of task-sharing models of care for emerging health priorities currently managed at the hospital level (eg, devolving mental health and non-communicable disease care to PHC level), establishing model PHC facilities as exemplars of best practice, and promoting evidence-based PHC interventions by competent, compassionate and respectful staff. ${ }^{8}$

It is within this context of PHC transformation that the Ethiopian Federal Ministry of Health (FMoH) was introduced to the Practical Approach to Care Kit (PACK) programme $^{9}$ by counterparts from South Africa and Botswana in 2016. Designed, implemented and tested in a South African context, ${ }^{10}{ }^{11}$ the PACK programme comprises the provision of carefully designed comprehensive and integrated clinical decision support, the PACK guide, using a structured implementation strategy in a PHC setting. Each of over 2300 recommendations in the guide is aligned to WHO guidance and global evidence, sourced and annually updated through the British Medical Journal evidence synthesis product, Best Practice, which is an online clinical decision support tool. ${ }^{12}$ The potential utility of PACK as a tool for health system strengthening in Ethiopia was recognised immediately. Of particular appeal to the Ethiopian $\mathrm{FMoH}$ was that PACK was provider-friendly, enabled a one-stop shop for comprehensive and integrated care, and was evidence-aligned, meaning that gold standard evidence was aligned with WHO guidance as well as to Ethiopian policies and guidelines. The process of adapting the PACK programme to the Ethiopian context (to become the Ethiopian Primary Health Care Clinical Guidelines; Ethiopian PHCG) was then initiated, with a view to scaling up nationally. In this paper we will describe how PACK was localised for Ethiopia so as to align with existing policies and ensure feasibility, highlighting the challenges encountered on the way, key lessons learnt and the opportunities afforded by linking Ethiopian PHCG localisation to a collaborative health systems research programme.
Box 1 Health and health-related indicators for Ethiopia

Socioeconomic status.

- Gross domestic product per capita: US\$706.8 in 2016. ${ }^{28}$

- Poverty head count ratio at $<\$ 1.90$ a day: $23.4 \%$ in $2016 .{ }^{29}$

Health resources.

- Per capita total expenditures on health: US\$24.3 in $2015 .^{28}$

- External resources for health (\% of total health expenditure): $15 \% .{ }^{30}$

- Out-of-pocket payments (\% total health expenditure): $38 \%{ }^{31}$

- Health workers per 1000 population: 0.044 physicians, 0.097 health officers, 0.84 nurses and 0.423 community health workers. ${ }^{6}$

Major health challenges.

- Maternal mortality: 412 per 100000 live births. ${ }^{32}$

- Communicable disease: HIV $0.9 \%$ in $15-49$ years. ${ }^{33}$

- Under 5 years stunting: $38 \%{ }^{34}$

- Mental health problems: schizophrenia $0.5 \%,{ }^{35}$ bipolar disorder $0.5 \%,{ }^{36}$ alcohol dependence $1.5 \%{ }^{37}$ and depression $5.0 \% .{ }^{38}$

- Other non-communicable diseases and risk factors: hypertension $16 \%$ of adults, ${ }^{39}$ elevated blood glucose $5.9 \%$ of adults, ${ }^{39}$ asthma $1.5 \%-3 \%{ }^{40} 41$ and cancer 64285 incident cases annually. ${ }^{42}$

Injuries: $3 \%$ of adults involved in a road traffic accident annually. ${ }^{43}$

\section{HEALTH AND HEALTHCARE IN ETHIOPIA}

The Ethiopian population is undergoing an epidemiological transition and now faces a triple burden of communicable diseases, reproductive health threats and undernutrition, combined with emerging health concerns in the area of mental health, other non-communicable diseases and injuries. ${ }^{13}$ Poverty remains a challenge despite $7.5 \%$ average annual growth of gross domestic product per capita from 2009 to $2015^{14}$ (see box 1). The health system is generally orientated to respond to acute episodes of illness, with healthcare providers tending to focus on the presenting health condition. ${ }^{8}{ }^{15}$ This is despite clear evidence of high levels of comorbidity for all chronic conditions, which adversely affect health outcomes and quality of life if not addressed adequately. ${ }^{16}$ For example, undetected depression in people with tuberculosis in Ethiopia is associated with increased mortality ${ }^{17}$ Even in the area of acute care, vertical programming (eg, HIV, tuberculosis, maternal health) has led to a proliferation of stand-alone clinical guidelines which promote fragmented care and form a barrier to comprehensively addressing patient needs. In recognition of these challenges, the current Health Sector Transformation Plan has person-centred care as a guiding principle. The integrated approach embedded within the PACK guide has been shown to result in modest improvements in the quality of care and health outcomes in the South African context $^{9-11}$ and has similar potential to promote a more holistic and person-centred approach to care in Ethiopia.

The structure of the health system in Ethiopia is illustrated in figure 1 . The primary care unit comprises a health centre with satellite health posts, linked by referral pathways to a primary hospital. The health centre and primary hospitals are the level at which the Ethiopian PHCG will be introduced. In rural areas, doctors are 
Box 2 Changes to the Practical Approach to Care Kit to form the Ethiopian PHCG

Rebranding as the Ethiopian Primary Health Care Clinical Guidelines (PHCG).

- Expansion to include common illness presentations of children aged 5 years and above.

- Customising the common symptom presentations to the local context.

- Adjustment of recommendations for medications and laboratory investigations to align with national recommendations for health centres. $^{44}$

- Expansion of existing content to address primary care priorities, for example, added focus on palliative care, and symptoms of locally salient acute infectious conditions (relapsing fever, typhus, cutaneous leishmaniasis), rheumatic heart disease and malnutrition.

- Addition of photographs depicting local skin conditions.

- Addition of communication skills to address the Federal Ministry of Health transformation agenda of 'creating compassionate, respectful and caring professionals'.

rarely found at the health centre level, with nurses, midwives and health officers providing most of the care. Health officers take a 4-year degree to equip them to take on a role intermediate between doctors and nurses; nurses are trained for 3 years and can be either BSc or diploma level. The population coverage of key health workers is given in box 1.

Healthcare planning is decentralised within the federal structure of Ethiopia, with an important role played by the regional health bureaus in setting strategic direction. District ('woreda') health offices also carry the responsibility of localising healthcare planning for their own populations. Any new health system intervention needs to have the full buy-in of these planners.

\section{LOCALISATION OF THE PRACTICAL APPROACH TO CARE KIT PROGRAMME TO THE ETHIOPIAN SETTING}

Ethiopian ownership of the PACK localisation process was apparent from the outset. However, the $\mathrm{FMoH}$ was also keen to benefit from the expertise and experience of the PACK developers, based at the Knowledge Translation Unit (KTU), University of Cape Town Lung Institute, South Africa. When the FMoH made contact with the KTU, they discovered that KTU had been collaborating with Addis Ababa University (AAU), Ethiopia, for several years on the primary care-based Programme for Improving Mental Health Care. ${ }^{18} 19$ An opportunity to support PACK localisation and implementation within the context of a research collaboration was identified. A research proposal was developed by King's College London (KCL), in collaboration with AAU, the KTU and the $\mathrm{FMoH}$, as part of an application for a UK National Institute of Health Research Global Health Research Unit: the ASSET project (heAlth Systems StrEng Thening in sub-Saharan Africa; www.healthasset.org). Even prior to acquiring funding, the PACK Global delivery lead and PACK Global engagement lead visited the $\mathrm{FMoH}$ in February 2017 to gain a better understanding of the health system context and the expectations with respect to localisation of PACK for Ethiopia and its implementation as the Ethiopian PHCG programme. This provided an opportunity for the $\mathrm{FMoH}$ team to gain a

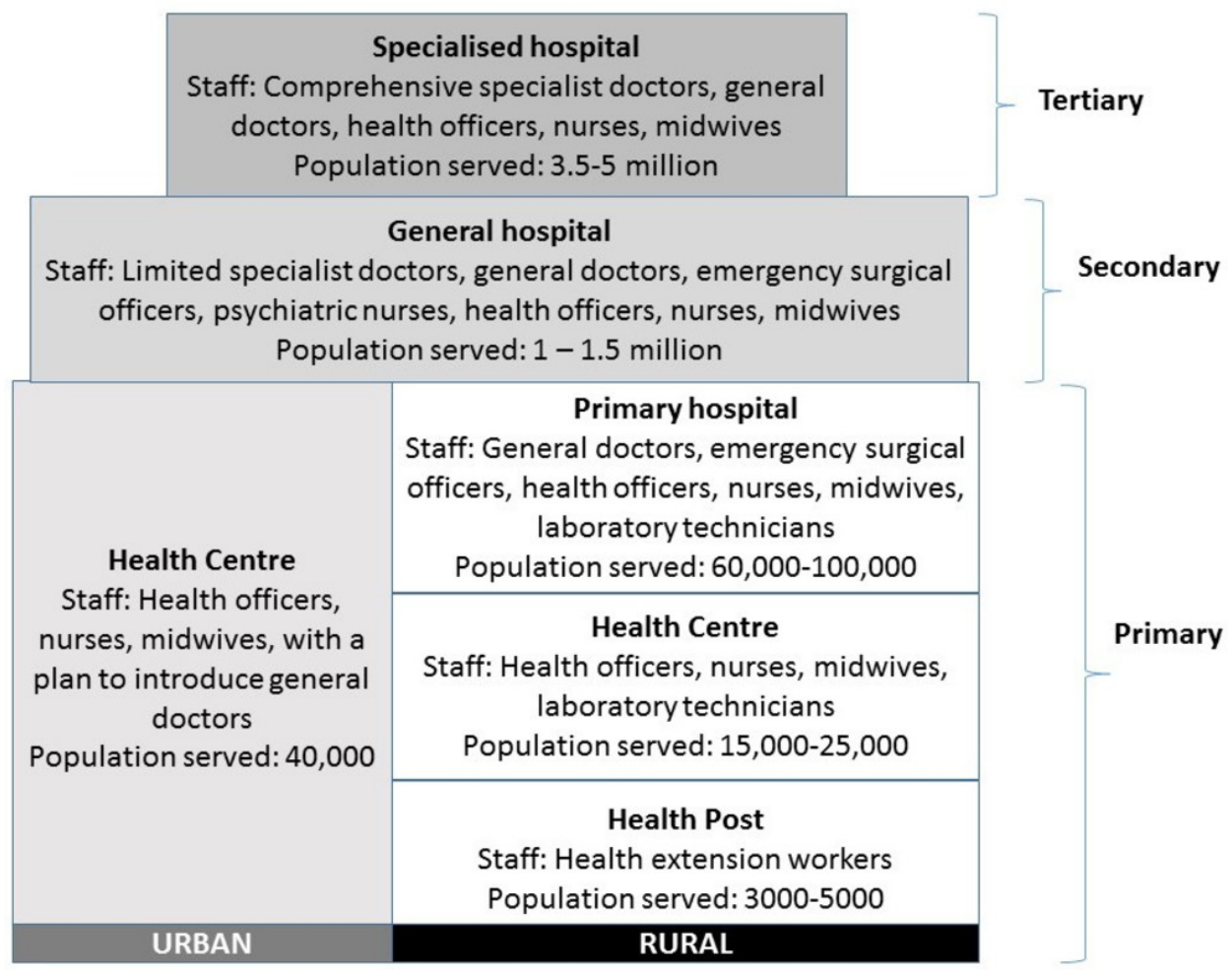

Figure 1 Tiers of the Ethiopian health system 


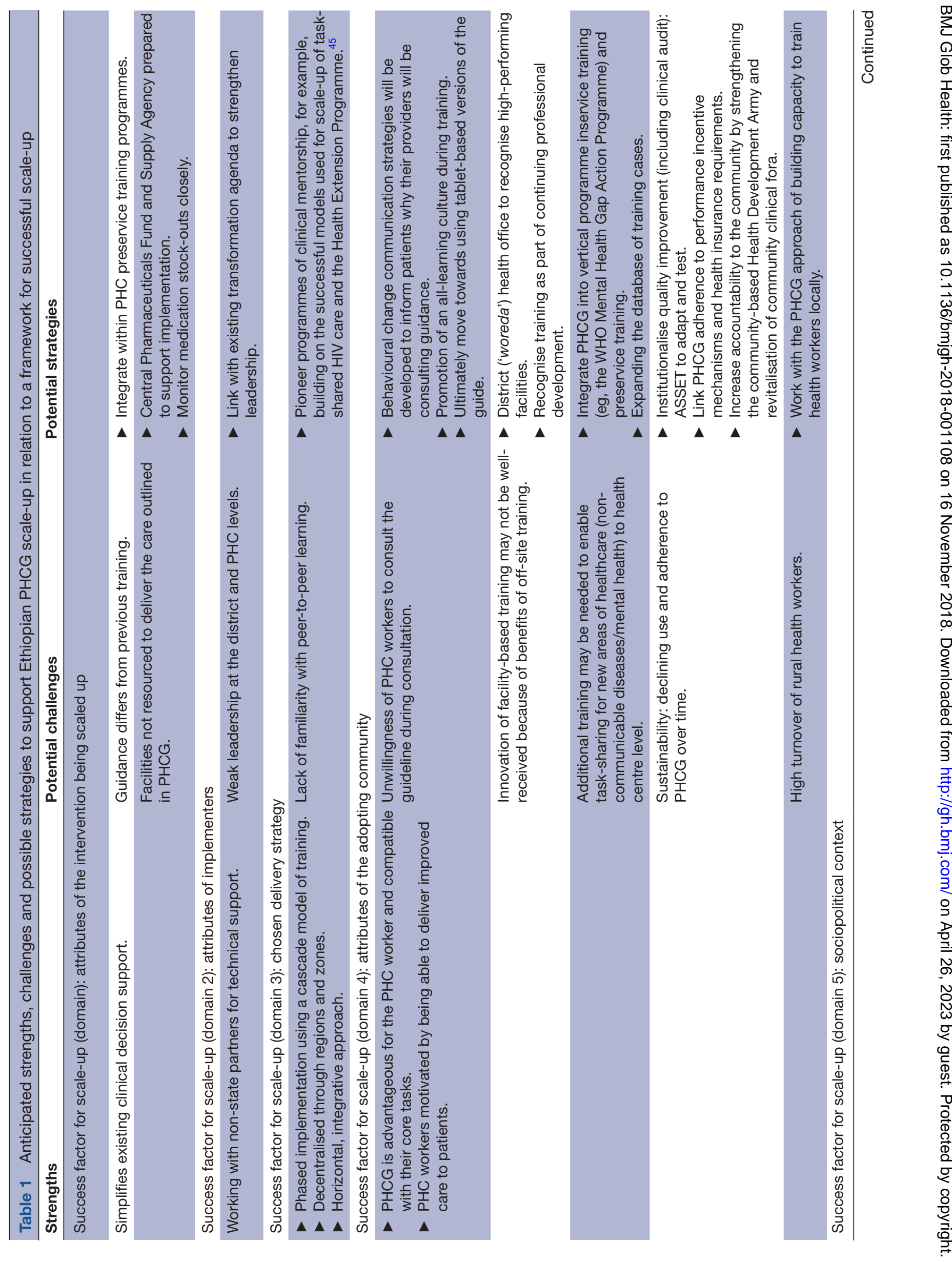


comprehensive understanding of the PACK programme and the toolkit which is available to support full localisation, implementation and scale-up. During the visit, time was also spent scoping and costing the PHCG programme for Ethiopia. Once ASSET funding has been secured, the FMoH embarked on a formal partnership with the KTU, KCL and AAU to assist with completion of the guide localisation and associated training materials and initial training, and to develop and evaluate health systems strengthening interventions to support the Ethiopian PHCG implementation.

The FMoH buy-in to PACK was such that there was a strong impetus to complete localisation within a period of months so that this key PHC transformation tool could be scaled up. A core team of eight Ethiopian technical experts worked full time on the localisation. An intensive mentorship package was provided by the KTU to complement the incountry content expertise, in particular with facilitating the consolidation of existing local guidelines and policies with the evidence-informed recommendations of PACK, and supporting integration of new content. ${ }^{20}$ The Ethiopia core team visited the KTU in Cape Town for a 5-day period, during which they worked closely with KTU mentors to become familiar with the PACK approach to, and tools for, content development, localisation and training. The process of localisation of complex and new clinical content was started, including scoping out child health priorities for inclusion. The Ethiopia team observed PACK in action in South African primary care during a facility-based PACK training session. This visit was followed 2 months later by a 2 -week intensive localisation workshop attended by the KTU mentors, Ethiopia core team and local experts to obtain consensus on contentious clinical recommendations and develop additional content for priority conditions. Around 30 Ethiopian clinical guidelines were reviewed in relation to the evidence-based guidance in Global PACK (see online supplementary file 1) before the guide was finalised.

Some of the key changes to the PACK guide are summarised in box 2 . These changes were based on the localisation workshops and consultation process, the FMoH experience of policy priorities and past scale-up programmes and local evidence from implementing integrated mental health in primary care in Ethiopia. ${ }^{19}$ Rebranding as the 'Ethiopian PHCG' was of fundamental importance to communicate to regional, zonal and district healthcare planners, as well as to PHC professionals, that the guide was an Ethiopian product which was relevant to their needs. Expanding the age range to which the guide catered was considered crucial to address the 5-14 age group, not covered by the widely implemented WHO Integrated Management of Newborn and Child Illness guidelines. ${ }^{21}$ Approximately $15 \%$ of patient contacts in PHC in Ethiopia are for this age group. ${ }^{22}$ Expanding to incorporate a broader range of acute infectious presentations (like a symptom-based approach to fever including relapsing fever and typhus, not included in the generic 
Table 2 Examples of approaches to monitoring and evaluation from the Federal Ministry of Health and the ASSET research programme

\begin{tabular}{|c|c|c|}
\hline \multirow[b]{2}{*}{ Domains of interest } & \multicolumn{2}{|l|}{ Planned evaluation } \\
\hline & Federal Ministry of Health & ASSET programme \\
\hline Health worker performance & $\begin{array}{l}\text { Numbers of health workers attending facility } \\
\text { training. } \\
\text { Change in knowledge/attitudes. } \\
\text { Self-reported fidelity to Ethiopia PHCG. }\end{array}$ & $\begin{array}{l}\text { Observed communication skills and delivery of } \\
\text { person-centred care. } \\
\text { Competence of health workers in detecting } \\
\text { non-communicable diseases against a gold } \\
\text { standard. } \\
\text { Observed fidelity to Ethiopia PHCG. }\end{array}$ \\
\hline Patient outcomes & $\begin{array}{l}\text { Quantitative and qualitative satisfaction with } \\
\text { care. } \\
\text { Contact coverage for comprehensive, integrated } \\
\text { primary care clinical services. } \\
\text { Facility-reported patient outcomes from service } \\
\text { monitoring data. }\end{array}$ & $\begin{array}{l}\text { Patient functioning and symptom control } \\
\text { measured using standardised measures. }\end{array}$ \\
\hline
\end{tabular}

ASSET, heAlth Systems StrEngThening in sub-Saharan Africa; PHCG, Primary Health Care Clinical Guidelines.

PACK Global guide template) was required to ensure that the guide could be truly comprehensive for the Ethiopian setting. Some symptom presentations, for example for depression, were adapted on the basis of previous work in Ethiopia. ${ }^{23}$

Although the PACK guide has the potential to demarcate the scope of practice for each of the health professionals working in primary care by colour-coding prescriptions, procedures, referrals and investigations, there was a need for greater flexibility in the Ethiopian PHCG. The human resource mix at a given level of the health system may vary depending on staff availability, which means that there is variability in the preferred professional to carry out a specific task. For example, in rural health facilities, nurses may prescribe medications, although when health officers are available they would be the preferred prescribers.

Once the initial localisation of the PACK guide to become the Ethiopian PHCG had taken place, a series of four consultative workshops were conducted with a broader stakeholder group of clinicians (including PHC nurses and health officers, emergency surgical officers, surgeons and other medical specialists), purposefully selected to have different levels of experience. As a cross-cutting healthcare programme, substantial efforts were also made to engage the relevant $\mathrm{FMoH}$ directorates, for example, Disease Control and Prevention, Maternal and Child Health, and the Health Extension Programme, to ensure full integration. Six pages of the Ethiopian PHCG (four symptom pages and two pages for chronic conditions) were pretested by nine PHC professionals of different professional backgrounds (health officers and nurses) working in three health centres in the capital city, Addis Ababa. The main feedback was very positive, with the health workers reporting that it was easy to understand and use and gave them greater confidence for care delivery. However, the health workers highlighted the challenge of availability of essential medications and laboratory investigations recommended in the guide, as well as the challenge of delivering care for conditions with which they had little familiarity, in particular, mental healthcare. Some health workers found the font to be too small and others expressed concern about what patients would think if a clinician checked a guideline in the middle of a consultation. The content of the symptom pages was reduced to allow an increase in the font size. The strategies to tackle the larger health system challenges to implementation are discussed in table 1.

The PACK training materials were also localised for the Ethiopian setting. Training cases were selected to emphasise areas where it was anticipated that the PHC professionals would have low levels of previous experience, for example, in the areas of non-communicable diseases and mental health, as well as priority programmes (eg, antenatal care). Ethiopia also opted to include training cases that integrated communication skills that are being implemented in South Africa ${ }^{24}$ : 'PRY' (Prepare, Relationship-building and find out whY the patient has come to consult) and 'ICE' (Ideas, Concerns and Expectations). This emphasis on clinical communication skills was in support of the Health Sector Transformation Plan agenda to promote compassionate, respectful clinicians.

\section{IMPLEMENTATION AND TRAINING FOR THE FIRST PHASE}

The scale-up of the Ethiopian PHCG is endorsed by the $\mathrm{FMoH}$ as a core programme activity, with committed funding at the national and local governmental level. A cascade model of training will be followed, with three levels of trainer: national master trainers, regional/zonal/ district master trainers and facility trainers. Training of national master trainers was undertaken in Addis Ababa in January 2018, and enjoyed high-level support with the State Minister of Health actively participating in sessions 
that model the onsite interactive training programme. ${ }^{25}$ The first phase of Ethiopian PHCG implementation will involve sequential roll-out to 400 health centres across all regions and city administrations in Ethiopia. Although it is ambitious to start implementation across a large number of facilities and settings, this is necessary to get political buy-in nationally and regionally and to stimulate momentum. The FMoH has been working closely with regional health bureaus to select facilities from high-performing districts based on the 'woreda' transformation criteria, to include a combination of facilities with high and low levels of patient flow. Facility readiness assessments have been undertaken in order to ensure that facilities have the requisite medication, equipment and human resources to deliver Ethiopia PHCG. In itself this process has already identified gaps in facility readiness, for example, availability of medications for mental health and other non-communicable diseases, which will need to be addressed as the programme proceeds.

A total of 94 zonal level master trainers have now been trained, with national master trainers mentored by the KTU staff. The FMoH has allocated budget, which has been transferred to the regional health bureaus so that they can direct the programme and will take responsibility for coordinating with the zonal and district health offices to support the next step: training of facility trainers. Facility trainers will receive 3.5 days of training to orientate them to PHCG and prepare them to lead facility-based training. In this way, the training of trainers will follow the usual scale-up structure. Facility trainers will then lead the weekly health centre-based training sessions, which will extend over a period of about 12 weeks. They will be supported by the zonal/district master trainers on a monthly basis. A dedicated team based at the $\mathrm{FMoH}$ and coordinating with the regional health bureaus will provide ongoing technical support, help with troubleshooting, and oversee monitoring and evaluation in order to ensure successful scale-up.

\section{MONITORING AND EVALUATION}

One of the distinguishing features of the scale-up of Ethiopian PHCG is the close working between policy-makers / planners $(\mathrm{FMoH})$ and health systems researchers. This is new territory for both sides of the collaboration in Ethiopia but has great potential to contribute to successful scale-up. Monitoring and evaluation activities for Ethiopian PHCG will occur at two levels: (1) more extensive, but less indepth, monitoring and evaluation of the $\mathrm{FMoH}$ first-phase implementation, incorporating 400 health care facilities over diverse regions; and (2) smaller scale, but more indepth evaluation of implementation through the ASSET project. ASSET will operate in three districts and across 18 PHC health centres and will function as a 'demonstration site' for Ethiopian PHCG. After a diagnostic phase to identify health system bottlenecks postimplementation of Ethiopian PHCG, ASSET will test health systems strengthening interventions to optimise the impact of the PHCG. These will include the introduction of quality improvement activities to support learning health systems, ${ }^{26}$ non-technical health worker skills to promote holistic care and mHealth innovations to support chronic care. In addition to measuring health system performance, ASSET will also evaluate impact at the level of patient outcomes. Implementers of the Ethiopian PHCG will provide input into implementation challenges and ASSET will seek to communicate learning from the demonstration sites in a timely fashion, to inform the ongoing scale-up. Examples of the types of complementary data to be generated by both the FMoH and ASSET are described in table 2.

\section{OPPORTUNITIES, CHALLENGES AND STRATEGIES}

The strong governmental commitment to primary care and population health within the Ethiopian health system combined with the widespread engagement of communities in health and healthcare provides an exciting opportunity for a rapid and successful scale-up of the Ethiopian PHCG. Some of the potential challenges to the scale-up of Ethiopian PHCG have been anticipated, based on the localisation process, experience of PACK scale-up in similar contexts and scale-up of other interventions within the Ethiopian context. These are summarised in table 1 , in relation to the success factors identified in a framework for scaling up global health interventions, ${ }^{27}$ with possible strategies that are being considered to overcome them.

\section{NEXT STEPS}

Phase 1 implementation of the Ethiopian PHCG is planned for 2018, moving to full scale-up across 3724 PHC facilities from 2019. The regional governments will allocate budget for implementation, as well as channelling funding from donors working in the area of PHC. The ASSET project activities will run alongside the scale-up, with a formative phase until early 2019, and then phases of piloting, implementation and evaluation of health systems strengthening interventions during 2019 and 2020. Routine indicators for ongoing monitoring of the operation of Ethiopian PHCG will be developed, informed by learning from the $400 \mathrm{FMoH}$ health centres and the findings from the ASSET demonstration sites. A consortium of partners is being established to support the sustainability of Ethiopian PHCG, with technical support, capacity-building and a process to allow ongoing modification and updating of the guideline. Further funds are being solicited to support the expansion of Ethiopian PHCG to include evidence-informed guidance on intrapartum care. In the future there is ambition to expand the PACK approach to different levels in the health system, including a guide for community-based health workers.

\section{CONCLUSION}

The localisation of PACK to the Ethiopian PHCG has been distinguished by strong leadership from the $\mathrm{FMoH}$ 
of Ethiopia and a productive collaboration with health systems research partners. Challenges include wider health system constraints, particularly availability of essential medications and laboratory investigations, and the need for additional training and supervisory support to deliver care for non-communicable diseases and mental health. The scale-up and evaluation of Ethiopia PHCG have the potential to drive the wider health system changes needed to address these challenges through the standardisation of expected clinical practice at the primary care level, and by so doing to promote quality healthcare for all.

\author{
Author affiliations \\ ${ }^{1}$ Federal Ministry of Health of Ethiopia, Addis Ababa, Ethiopia \\ ${ }^{2}$ Institute of Psychiatry, Psychology and Neuroscience, Health Service and \\ Population Research Department, Centre for Global Mental Health, King's College \\ London, London, UK \\ ${ }^{3}$ Centre for Innovative Drug Development and Therapeutic Trials for Africa (CDT- \\ Africa), College of Health Sciences, Addis Ababa University, Addis Ababa, Ethiopia \\ ${ }^{4}$ Department of Psychiatry, School of Medicine, College of Health Sciences, Addis \\ Ababa University, Addis Ababa, Ethiopia \\ ${ }^{5}$ Technical Assistant to the Clinical Services Directorate, Federal Ministry of Health \\ of Ethiopia, Addis Ababa, Ethiopia \\ ${ }^{6}$ Knowledge Translation Unit, University of Cape Town Lung Institute, Cape Town, \\ South Africa \\ ${ }^{7}$ Department of Medicine, University of Cape Town, Cape Town, South Africa \\ ${ }^{8}$ Department of Reproductive Health and Health Service Management, School of \\ Public Health, College of Health Sciences, Addis Ababa University, Addis Ababa, \\ Ethiopia \\ ${ }^{9}$ Institute of Palliative Care, Kozhikode, Kerala, India \\ ${ }^{10}$ Tropical Health Education Trust and Jimma University Chronic Disease Project, \\ Jimma, Ethiopia \\ ${ }^{11}$ JSI/USAID Transform: Primary Health Care, Addis Ababa, Ethiopia \\ ${ }^{12}$ BMJ Knowledge Centre Department, BMA House, London, UK \\ ${ }^{13}$ Health Systems Research Unit, South African Medical Research Council, Cape \\ Town, South Africa \\ ${ }^{14}$ King's Global Health Research Institute, King's College London, London, UK
}

Acknowledgements The authors would like to express their gratitude to the Ethiopian clinical content experts who contributed to the localisation of the Ethiopian PHCG. The authors also gratefully acknowledge the important contributions of Dr Ermias Diro and Dr Hassan Mohammed to the localisation of the Ethiopian PHCG. We are grateful to our funders for making the work possible.

Contributors DT and DG led the initial PACK localisation in Ethiopia, which was subsequently continued by YM. SE, TT, SS, WW and YM were members of the PACK core technical team in Ethiopia. TA and MW are involved in phase 1 implementation of PACK. CH was a PACK content reviewer for mental health. MJP, CH and DT are investigators on ASSET. TE led on engagement between the BMJ, KTU and the Ethiopian FMoH. AA, CW, SCP, LA and CJR provided content and training mentorship from the KTU, with oversight by RVC and LF. TE provided overall support on engagement and project management. LF, CH, YM, DT and MJP conceptualised the paper. $\mathrm{YM}$ and $\mathrm{CH}$ wrote the first draft. All authors contributed intellectual content, edited the manuscript and approved the final version for submission.

Funding KTU's mentorship of the Ethiopian localisation work and the ASSET research programme are supported by the UK's National Institute of Health Research (NIHR) using Official Development Assistance (ODA) funding (NIHR Global Health Research Unit on Health Systems Strengthening in Sub-Saharan Africa at King's College London (16/136/54)). The views expressed in this publication are those of the author(s) and not necessarily those of the NHS, the National Institute for Health Research or the Department of Health and Social Care, England. TD's time was supported by the South African Medical Research Council. The Ethiopian core technical team were funded by USAID through the JSI Urban Health Strengthening Project. Two of the incountry PACK guide review meetings were funded by ICAP (International Centre for AIDS care and treatment Programme), Columbia University Mailman School of Public Health.
Competing interests The authors have read and understood the BMJ policy on declaration of interests and declare that AA, CJR, RVC, LF, SCP, CW and LA are employees of the KTU. TE is a contractor for both KTU and BMJ, London, UK. Since August 2015 KTU and BMJ have been engaged in a non-profit strategic partnership to provide continuous evidence updates for PACK, expand PACK-related supported services to countries and organisations as requested, and where appropriate licence PACK content. KTU and BMJ cofund core positions, including a PACK Global Development Director (TE), and receive no profits from the partnership. TD is an employee of the South African Medical Research Council. PACK receives no funding from the pharmaceutical industry. This paper forms part of a collection on PACK sponsored by the BMJ to profile the contribution of PACK across several countries towards the realisation of comprehensive primary healthcare as envisaged in the Declaration of Alma Ata, during its 40th anniversary.

Patient consent Not required.

Provenance and peer review Not commissioned; externally peer reviewed.

Data sharing statement № additional data are available.

Open access This is an open access article distributed in accordance with the Creative Commons Attribution Non Commercial (CC BY-NC 4.0) license, which permits others to distribute, remix, adapt, build upon this work non-commercially, and license their derivative works on different terms, provided the original work is properly cited, appropriate credit is given, any changes made indicated, and the use is non-commercial. See: http://creativecommons.org/licenses/by-nc/4.0

\section{REFERENCES}

1. World Health Organization, 1978. Declaration of Alma Ata. Available from: http://www.who.int/publications/almaata_declaration_en.pdf? $\mathrm{ua}=1 \& \mathrm{ua}=1$

2. Kruk ME, Chukwuma A, Mbaruku G, et al. Variation in quality of primary-care services in Kenya, Malawi, Namibia, Rwanda, Senegal, Uganda and the United Republic of Tanzania. Bull World Health Organ 2017;95:408-18.

3. Leslie HH, Malata A, Ndiaye $\mathrm{Y}$, et al. Effective coverage of primary care services in eight high-mortality countries. BMJ Glob Health 2017;2:e000424.

4. Population Reference Bureau. 2017 World Population Data Sheet with a special focus on youth, 2017. Available from: https://www. prb.org/2017-world-population-data-sheet/ [Accessed 6 Aug 2018].

5. Federal Democratic Republic of Ethiopia. CSA population projection of Ethiopia for all regions 2014-2017. Addis Ababa, Ethiopia: Central Statistical Agency, 2017

6. Federal Ministry of Health. Health \& health-related indicators: 2009 EFY (2016/2017. Addis Ababa, Ethiopia: Federal Ministry of Health, 2018.

7. National Planning Commission of Ethiopia and United Nations. Millennium development goals report 2014 Ethiopia: assessment of Ethiopia's Progress towards the MDGs. Addis Ababa, Ethiopia: National Planning Commission of Ethiopia and the United Nations in Ethiopia, 2015

8. Federal Democratic Republic of Ethiopia Ministry of Health. Health sector transformation plan: 2015/2016-2019/2020. Addis Ababa: $\mathrm{FMOH}, 2015$

9. Fairall L, Bateman E, Cornick R, et al. Innovating to improve primary care in less developed countries: towards a global model. BMJ Innov 2015;1:196-203.

10. Fairall L, Bachmann MO, Lombard C, et al. Task shifting of antiretroviral treatment from doctors to primary-care nurses in South Africa (STRETCH): a pragmatic, parallel, cluster-randomised trial. Lancet 2012;380:889-98.

11. Fairall LR, Folb N, Timmerman V, et al. Educational outreach with an integrated clinical tool for nurse-led non-communicable chronic disease management in primary care in South Africa: a pragmatic cluster randomised controlled trial. PLoS Med 2016;13:e1002178.

12. Cornick R, Picken S, Wattrus $C$, et al. The Practical Approach to Care Kit (PACK) guide: developing a clinical decision support tool to simplify, standardise and strengthen primary healthcare delivery. BMJ Glob Health 2018;3:e000962.

13. Misganaw A, Haregu TN, Deribe K, et al. National mortality burden due to communicable, non-communicable, and other diseases in Ethiopia, 1990-2015: findings from the global burden of disease study 2015. Popul Health Metr 2017;15:29.

14. World Bank. World development indicators 2017. Washington, DC: World Bank, 2017

15. Hanlon C, Eshetu T, Alemayehu D, et al. Health system governance to support scale up of mental health care in Ethiopia: a qualitative study. Int J Ment Health Syst 2017;11:38. 
16. World Health Organization and Calouste Gulbenkian Foundation. Integrating the response to mental disorders and other chronic diseases in health care systems. Geneva: World Health Organization, 2014.

17. Ambaw F, Mayston R, Hanlon C. Impact of untreated depression on tuberculosis treatment outcomes, disability and quality of life in Ethiopia. Bulletin of the World Health Organisation 2018:96:243-55.

18. Lund C, Tomlinson M, De Silva M, et al. PRIME: a programme to reduce the treatment gap for mental disorders in five low- and middle-income countries. PLoS Med 2012;9:e1001359.

19. Fekadu A, Hanlon C, Medhin G, et al. Development of a scalable mental healthcare plan for a rural district in Ethiopia. $\mathrm{Br} J$ Psychiatry 2016;208(Suppl 56):s4-s12.

20. Cornick R, Wattrus $C$, Eastman $T$, et al. Crossing borders: the PACK experience of spreading a complex health system intervention across low-income and middle-income countries. BMJ Glob Health 2018;3(Suppl 5):e001088.

21. World Health Organization. Integrated management of neonatal and childhood illnesses. Geneva: WHO, 2003.

22. Federal Democratic Republic of Ethiopia Ministry of Health. Health and health-related indicators 2009 EFY (2016/2017. Addis Ababa, Ethiopia: Federal Ministry of Health, 2017.

23. Hanlon C, Medhin G, Selamu M, et al. Validity of brief screening questionnaires to detect depression in primary care in Ethiopia. $J$ Affect Disord 2015;186:32-9.

24. Petersen I, Bhana A, Folb N, et al. Collaborative care for the detection and management of depression among adults with hypertension in South Africa: study protocol for the PRIME-SA randomised controlled trial. Trials 2018;19:192.

25. Simelane ML, Georgeu-Pepper D, Ras C-J, et al. The Practical Approach to Care Kit (PACK) training programme: scaling up and sustaining support for health workers to improve primary care. BMJ Glob Health 2018;3(Suppl 5):e001124.

26. English M, Irimu G, Agweyu A, et al. Building learning health systems to accelerate research and improve outcomes of clinical care in low- and middle-income countries. PLoS Med 2016;13:e1001991.

27. Yamey G. Scaling up global health interventions: a proposed framework for success. PLoS Med 2011;8:e1001049.

28. World Bank. World development indicators database. Available from: http://databank.worldbank.org/data/reports.aspx?source=worlddevelopment-indicators\#\%20World\%20Bank

29. National Plan Commission of the Federal Democratic Republic of Ethiopia. The 2017 voluntary national reviews on SDGs of Ethiopia: government commitments, national ownership and performance trends. Addis Ababa, Ethiopia: Federal Democratic Republic of Ethiopia, 2017.

30. Federal Democratic Republic of Ethiopia Ministry of Health. The Ethiopia sixth health accounts, 2013/14: statistical report. Addis Ababa, Ethiopia: Federal Ministry of Health, 2017.
31. WHO Regional Office for Africa. State of health financing in the African Region. Brazzaville, Republic of Congo: WHO Regional Office for Africa, 2013

32. WHO. UNICEF, UNFPA, et al. Geneva: World Health Organization, Maternal mortality in 1990-2015. Ethiopia. Available from: http:// www.who.int/gho/maternal_health/countries/eth.pdf [Accessed accessed 2nd July 2018].

33. Central Statistical Agency (CSA) [Ethiopia] and ICF. Ethiopia demographic and health survey 2016: HIV report. Addis Ababa, Ethiopia, and Rockville, Maryland, USA: CSA and ICF, 2018

34. Central Statistical Agency [Ethiopia] and ICF International. Ethiopia demographic and health survey 2016: key indicators report. Addis Ababa, Ethiopia and Rockville, Maryland, USA: Central Statistical Agency and ICF., 2016.

35. Kebede D, Alem A, Shibre T, et al. The sociodemographic correlates of schizophrenia in Butajira, rural Ethiopia. Schizophr Res 2004;69-133-41.

36. Kebede D, Alem A, Shibre T, et al. Socio-demographic correlates of bipolar disorder in Butajira, rural Ethiopia. East Afr Med $J$ 2005;82:34-9.

37. Fekadu A, Alem A, Hanlon C. Alcohol and drug abuse in Ethiopia: past, present and future. African Journal of Drug and Alcohol Studies 2007;6:39-53.

38. Federal Democratic Republic of Ethiopia Ministry of Health. National mental health strategy, 2012/13-2015/16. Addis Ababa: Federal Ministry of Health, 2012.

39. Ethiopian Public Health Institute Health System Research Directorate. Ethiopia STEPS survey 2015. Addis Ababa: Ethiopian Public Health Institute, 2015.

40. Lai CK, Beasley R, Crane J, et al. Global variation in the prevalence and severity of asthma symptoms: phase three of the International Study of Asthma and Allergies in Childhood (ISAAC). Thorax 2009;64:476-83.

41. To T, Stanojevic S, Moores G, et al. Global asthma prevalence in adults: findings from the cross-sectional world health survey. $B M C$ Public Health 2012;12:204.

42. Memirie ST, Habtemariam MK, Asefa M, et al. Estimates of Cancer Incidence in Ethiopia in 2015 Using Population-Based Registry Data. $J$ Glob Oncol 2018;4:1-11.

43. Gebremichael M, Guta M, Gedefaw M. Prevalence and determinants of road traffic injuries in Ethiopia: Based on the 2015 STEPS survey findings. Ethiopian Journal of Health Development 2017;31:340-7.

44. Ethiopian Food Medicines and Healthcare Administration and Control Authority (EFMHACA). List of medicine for health centers, 2012. Available from:http://www.fmhaca.gov.et/documents/List of Medicine_for_Health_Centers.pdf [Accessed 7 Aug 2018].

45. Mengistu B, Karim AM, Eniyew A, et al. Effect of performance review and clinical mentoring meetings (PRCMM) on recording of community case management by health extension workers in Ethiopia. Ethiop Med J 2014;52:73-81. 